\title{
Colonic preservation reduces need for parenteral therapy, increases incidence of renal stones, but does not change high prevalence of gall stones in patients with a short bowel
}

\author{
J M D Nightingale, J E Lennard-Jones, D J Gertner, S R Wood, C I Bartram
}

\begin{abstract}
Forty six patients with less than $200 \mathrm{~cm}$ of normal jejunum and no functioning colon were compared with 38 patients with similar jejunal lengths in continuity with a functioning colon. Women predominated (67\%), and the most common diagnosis in each group was Crohn's disease ( 33 of 46 no colon, 16 of 38 with colon). All patients without a colon and less than $85 \mathrm{~cm}$ of jejunum and all those with a colon and less than $45 \mathrm{~cm}$ jejunum needed long term parenteral nutrition. Six months after the last resection 12 of 17 patients with less than $100 \mathrm{~cm}$ jejunum and no colon needed intravenous supplements compared with 7 of 21 with a colon. Between 6 months and 2 years, little change occurred in the nutritional/fluid requirements in either group, though there was weight gain. Of 71 patients assessed clinically at a median of 5 years, none with more than $\mathbf{5 0}$ $\mathrm{cm}$ of jejunum and a colon needed parenteral supplements. Most (25 of 27) of those without a colon who did not need parenteral supplements required oral electrolyte replacement compared with few (4 of 27) with a colon. None of the patients without a colon developed symptomatic renal stones compared with 9 of 38 $(24 \%)$ with a colon $(p<0 \cdot 001)$. Stone analysis in three patients showed calcium oxalate. Gall stone prevalence was high but equal in the two groups $-43 \%$ of those without and $44 \%$ of those with a colon.
\end{abstract}

(Gut 1992; 33: 1493-1497)

Most of the classic work published about patients with a short residual length of intestine has been on those with jejunum in continuity with colon. ${ }^{1-3}$ We are now managing an increasing number of patients with a high jejunostomy. This is mainly because the colon is often removed during the surgical treatment of Crohn's disease. These

Department of

Gastroenterology, St

Mark's Hospital, London

J M D Nightingale

J E Lennard-Jones

D J Gertner

S R Wood

C I Bartram

Correspondence to:

Professor J E Lennard-Jones,

Department of

Gastroenterology, St Mark's

Hospital, City Road, London ECIV 2PS

Accepted for publication

6 April 1992

\begin{tabular}{lcl}
\hline & No colon & Colon present $^{\star}$ \\
\hline Total no (sex) & $46(31 \mathrm{~F})$ & $38(26 \mathrm{~F})$ \\
Median jejunal length $(\mathrm{cm})$ & $115(20-190)$ & $90(0-190)$ \\
Diagnosis: & 33 & 16 \\
Crohn's disease & 2 & 6 \\
Ischaemia & 3 & 5 \\
Irradiation & 5 & 5 \\
Ulcerative colitis & - & 5 \\
Volvulus & 1 & 1 \\
Adhesions & 1 & 1 \\
Diverticular disease & 1 & \\
Desmoid & & \\
\hline
\end{tabular}

^Seven have ileocaecal valve, and 31 jejunocolic anastomosis.
TABLE I Patient details patients have problems of high intestinal losses of water, sodium, and magnesium.

In this study we compare patients with a high jejunostomy and others with a similar length of jejunum in continuity with at least half of the colon. The nutritional, sodium and magnesium treatment in these 2 groups was examined 6 months and 2 years after the last intestinal resection. At an assessment visit (median 5 years) an ultrasound examination of the gall bladder and kidneys was performed to determine the prevalence of gall stones and renal stones.

\section{Methods}

Patients managed at this hospital during the period 1980-90 with less than $200 \mathrm{~cm}$ of residual small bowel were identified. They were included in this study only if six months had elapsed since their last intestinal resection and if they had no overt disease in the remaining bowel.

The study was divided into two parts:

(1) The case record of each patient was reviewed and information recorded on diagnosis, date(s) of resection(s), the number of small bowel resections, and the length resected. The length of remaining small intestine from the duodenojejunal flexure was determined either at operation or from a barium follow through examination. ${ }^{4}$ Nutritional, salt, and magnesium supplements at 6 months and 2 years after the last resection were noted. The presence of symptomatic or incidentally found renal stones or gall stones, or both, was noted.

(2) As many of the patients as possible were seen and a record was made of all nutritional and electrolyte therapy. Their quality of life was assessed simply and height and weight were measured. A blood sample was taken for serum magnesium determination and a random urine sample for sodium measurement. An ultrasound examination of the kidneys and biliary system was performed.

\section{STATISTICAL ANALYSIS}

Comparisons between the two groups of patients for jejunal length, age, time from last resection, and body mass index were made using the MannWhitney $U$ test, and for the number with renal stones, gall stones, or receiving magnesium supplements using Fisher's exact test.

Results

The case notes showed that 86 patients fulfilled 
the entry criteria, and 71 of these patients were seen. In 61 patients the bowel length was determined at operation and in 25 from a barium follow through examination. ${ }^{4}$

\section{CLINICAL FEATURES OF 86 PATIENTS}

Women made up the majority $(67 \%)$ of patients in all diagnostic groups except intestinal volvulus ( 1 of 5 ). In 14 patients the total length of small intestine removed was known (median $125 \mathrm{~cm}$, range $60-240$ ).

\section{Classification}

Two patients had had predominantly jejunal resections with restoration of continuity, both for Crohn's disease. These two patients were well two years after the last resection, needing no supplements or drugs. The other 84 patients (Table I) fell into two groups, those with a short length of residual jejunum and no functioning colon and those with a similar length of jejunum in continuity with a functioning colon. The length of residual jejunum was not significantly different between the two groups. Of the 46 patients without a functioning colon, 43 had a jejunostomy and three a jejunorectal anastomosis. The 38 patients with a functioning colon
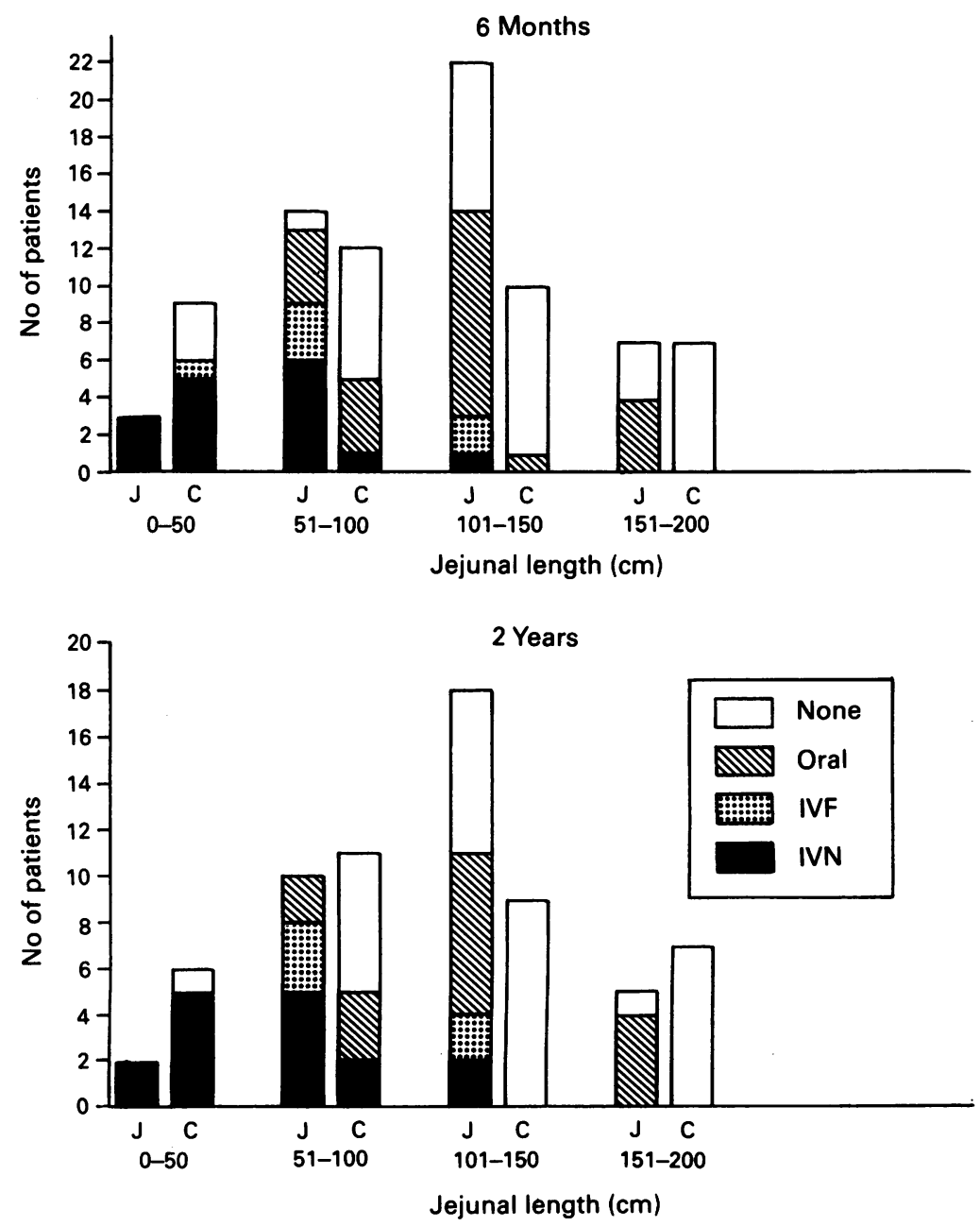

Figure 1: Intravenous nutrition (IVN), intravenous fluid and electrolyte (IVF), and oral electrolyte supplements received by patients with less than $200 \mathrm{~cm}$ jejunum at (A) 6 months $(n=84)$ and $(B) 2$ years $(n=68)$ after the last small bowel resection. $\mathcal{F}=$ mainly jejunum remaining and no colon. $C=j$ jejunum in continuity with a functioning colon. (of at least half its length) included 29 with jejunocolic and two duodenocolic anastomoses and seven patients with a reduced length of jejunum anastomosed to a short length of ileum with an intact ileocaecal valve. Four patients had a colostomy.

\section{Diagnoses}

The most common diagnosis in each group was Crohn's disease (Table I). Patients with Crohn's disease and no colon had undergone a median of four small intestinal resections (range 1-12) over a median of 11 years (1-26) compared with three resections (range 2-6) over a median of 14 years (range 0-29) in those with a colon. Five patients had jejunostomies for complications relating to the surgery of ulcerative colitis. Ischaemia mainly resulted in colonic preservation (6 of 8) and affected an older age group (median age 57 years (23-68)). Of the eight patients with irradiation damage, five had primarily gynaecological cancers, two carcinoma of colon and one seminoma. The median time from irradiation to having a small intestinal length of less than 200 $\mathrm{cm}$ was 5 years $(1-16)$.

\section{FLUID/NUTRITIONAL SUPPLEMENTS ANDSTATUS}

All patients without a functioning colon and less than $85 \mathrm{~cm}$ residual jejunum and all those with a colon and less than $45 \mathrm{~cm}$ of jejunum needed parenteral nutrition at all times.

Assessment at six months (84 patients)

As seen in Figure 1A, the major difference between the two groups was in patients with a jejunal length of $51-100 \mathrm{~cm}$; 9 of the $14(64 \%)$ patients without a colon required parenteral supplements compared with only one of $12(8 \%)$ with a colon. With a jejunal length of less than 50 $\mathrm{cm}$ all three patients without a colon needed parenteral supplements compared with 6 of 9 patients with a colon. When the jejunal length was more than $100 \mathrm{~cm}$ only 3 of $22(14 \%)$ of those without a colon and none of the 17 patients with a colon needed parenteral supplements.

\section{Assessment at two years}

Information was obtained on 68 of the 84 patients at two years: two died within the 2 year period, one patient was lost to follow up, and 13 patients had not reached 2 years.

The proportion of patients receiving parenteral supplements was similar to that at six months (Fig 1B). Of those patients with less than $50 \mathrm{~cm}$ of jejunum, both without a colon and 5 of 6 with a colon were receiving parenteral supplements. In the $51-100 \mathrm{~cm}$ range 8 of $10(80 \%)$ without a colon and 2 of $11(18 \%)$ with a colon received parenteral supplements. Three of the 18 without a colon and more than $100 \mathrm{~cm}$ jejunum received parenteral supplements compared with none of the 15 with a colon. 


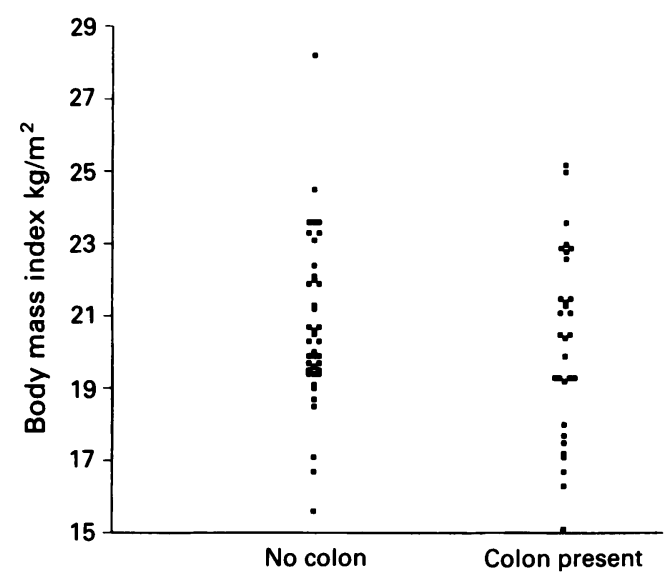

Figure 2: Body mass indices for patients with less than 200 cm jejunum at assessment visit.

outpatients. Their median age was 51 years (range 20-75) and the visit was at a median time of 59 months from the last resection. The groups were not significantly different from each other in terms of patient age or time from the last resection.

The median body mass index was not significantly different between the two groups (Fig 2); (median of 71 patients $20 \cdot 4$, range $15 \cdot 1-28 \cdot 2$ ), only 11 of 71 patients had a body mass index below the normal lower limit of 19. All the patients receiving a parenteral supplement took meals, though these might be reduced in size to decrease stomal output or diarrhoea, or fat content in those with a colon. Fifty patients were at full time work or looking after home and family unaided and 15 were at work part time or looking after home and family with help. Only 6 of all 71 patients were leading a restricted life and in most cases the disability was due to another condition.

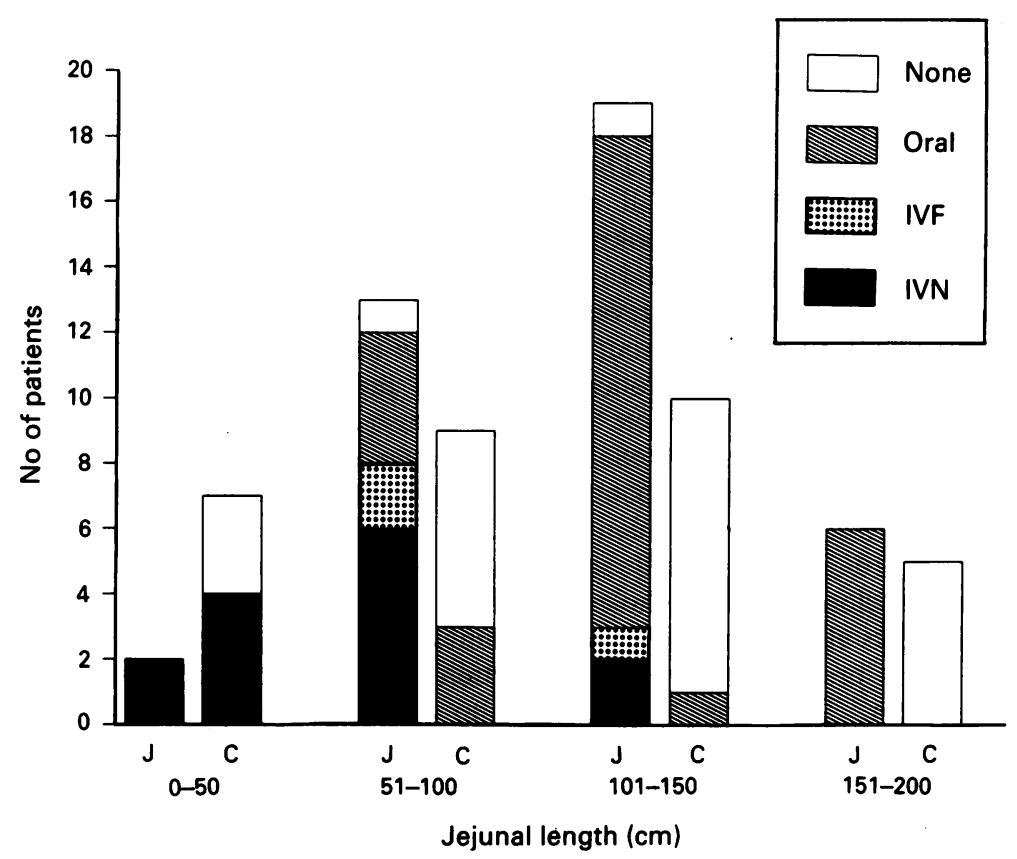

Figure 3: Intravenous nutrition (IVN), intravenous fluid and electrolyte (IVF), and oral electrolyte supplements needed at the assessment visit (median 5 years) in 71 patients with less than $200 \mathrm{~cm}$ jejunum. $\mathcal{F}=$ mainly jejunum remaining and no colon. $C=j e j u n u m$ in continuity with a functioning colon.
Figure 3 shows a similar situation to that at six months and two years with regards to the need for parenteral supplements. Of the 17 patients receiving parenteral supplements, only three, all without a colon, were receiving parenteral fluid and no nutrients. The two patients with a colon and jejunal lengths of 65 and $70 \mathrm{~cm}$ who were receiving parenteral supplements at two years had been able to stop them. All but two patients without a colon and not on parenteral supplements needed daily oral salt supplements. Some of the patients without a colon were probably salt depleted because 11 of 39 had a urinary sodium of less than $10 \mathrm{mmol} / \mathrm{l}$. Only 4 of the 27 who had a colon and were not taking parenteral supplements took an oral salt supplement and none had a low urinary sodium concentration. Table 2 shows that 31 of $40(78 \%)$ of those without a colon and 15 of $31(48 \%)$ with a colon took a magnesium supplement or had a low serum magnesium concentration $(p<0.05)$; no patient exhibited symptoms or signs of magnesium deficiency. Of the 19 patients taking oral magnesium oxide ( 3 to 8 capsules daily each containing $4 \mathrm{mmol}$ magnesium) 10 of 12 of those without a colon had a serum magnesium concentration less than $0.7 \mathrm{mmol} / \mathrm{l}$ (in 5 less than $0.6 \mathrm{mmol} / \mathrm{l}$ ) compared with 2 of 7 with a colon (none less than $0.6 \mathrm{mmol} / \mathrm{l}$. Total serum calcium was not different between the two groups and was less than $2 \cdot 2$ $\mathrm{mmol} / \mathrm{l}$ in 15 of the 71 patients and serum potassium was less than $3.5 \mathrm{mmol} / \mathrm{l}$ in 3 of 70 patients.

Seven of 27 patients without a colon and not receiving parenteral supplements were taking an oral nutrient supplement in addition to meals compared with 15 of 27 of those with a colon. Only four patients (two in each group) took the nutrient solution through a nasogastric tube at night.

\section{RENAL STONES}

No patient without a functioning colon developed symptomatic renal stones; however 9 of $38(24 \%)(\mathrm{p}<0.001)$ of those with a colon developed renal stones after a median time of 22 months (2-67); analysis in three showed calcium oxalate. Subsequent ultrasound scanning at the assessment visit showed the presence of persistent renal stones in 5 of $31(16 \%)$ with a colon and 0 of 39 without a colon.

\section{GALL STONES}

Subsequent to the last resection, one patient without a colon and two with a functioning colon had undergone cholecystectomy (Table III). An ultrasound of the gall bladder in 35 patients without a colon at a median time of 51 months (6-

TABLE II Magnesium status at assessment visit

\begin{tabular}{lll}
\hline & $\begin{array}{l}\text { No colon } \\
(n=40)\end{array}$ & $\begin{array}{l}\text { Colon present } \\
(n=31)\end{array}$ \\
\hline $\begin{array}{l}\text { Magnesium supplements: } \\
\text { Parenteral }\end{array}$ & 12 & 4 \\
$\begin{array}{l}\text { Oral } \\
\text { No magnesium supplements: } \\
\text { Serum Mg }<0 \cdot 7 \mathrm{mmol} / \mathrm{l}\end{array}$ & 12 & 7 \\
$\quad$ Normal & 9 & 4 \\
\hline
\end{tabular}


TABLE III Gall stones after small intestinal resection

\begin{tabular}{lll}
\hline & $\begin{array}{l}\text { No colon } \\
(n=46)\end{array}$ & $\begin{array}{l}\text { Colon present } \\
(n=38)\end{array}$ \\
\hline Cholecystectomy: & & \\
$\quad$ Before resection & 4 & 3 \\
$\quad$ After resection & 1 & 2 \\
Ultrasound: & 12 & 10 \\
$\quad$ Stones & 23 & 19 \\
$\quad$ No stones & 6 & 4 \\
Not followed & 43 & 44 \\
Prevalence (\%) & & \\
\hline
\end{tabular}

^Not included in prevalence calculation.

343) after the last small intestinal resection showed asymptomatic gall stones in 12; in 29 patients with a colon at a median time of 54 months (7-199) gall stones were found in 10. To calculate the overall prevalence of gall stones in patients with less than $200 \mathrm{~cm}$ jejunum, the seven patients who had had a cholecystectomy before their last resection are included. This gives a prevalence of gall stones of 17 of $40(43 \%)$ in patients without a colon and 15 of $34(44 \%)$ in those with a colon. Although the numbers are small, there did not seem to be a predominance of gall stones in any one diagnostic group. Of significance was the predominance of gall stones in men (17 of $27(63 \%))$ compared with women $(15 / 47(32 \%)(p<0.05))$.

\section{Discussion}

This is the largest review of patients with a short bowel and a residual jejunal length of less than $200 \mathrm{~cm}$. The commonest reason reported for a resection of a long length of small intestine in 1912 was strangulated hernia'; in 1935 it was intestinal volvulus ${ }^{2}$; in 1969 , superior mesenteric artery thrombosis ${ }^{3}$; and in 1991 we have shown it to be Crohn's disease. Most of the patients in this study had lost more than half, and some more than $90 \%$ of their small intestine, if the average normal length of $500 \mathrm{~cm}$ (range 302-777) in subjects with a normal bowel and in patients with Crohn's disease is accepted.

This study shows that after jejunoileal resection preservation of at least half of the colon is beneficial and is equivalent to about $50 \mathrm{~cm}$ of small intestine in terms of the need for parenteral supplements. We have shown that patients with a jejunostomy are likely to need long term parenteral supplements if the jejunal length is less than about $100 \mathrm{~cm}$, compared with about $50 \mathrm{~cm}$ in those in whom the colon has been preserved. This is in keeping with our previous finding that net secretion occurs in patients with a jejunostomy when the jejunal length is less than $100 \mathrm{~cm} .{ }^{6}$ Our findings are not dissimilar to those of Gouttebel who observed that if $110-120 \mathrm{~cm}$ of small intestine remained without a colon patients did not need parenteral supplements after three months, whereas if the colon was present the corresponding length was $50-70 \mathrm{~cm} .^{7}$ There are case reports of patients with enterocolic anastomoses surviving without parenteral support with very short, ${ }^{8}$ or even no, remaining jejunum ${ }^{910}$ but their quality of life was usually poor. Conservation of the colon is beneficial because it absorbs water, sodium, ${ }^{11-14}$ calcium, ${ }^{15}$ some nutrients, ${ }^{16}$ maintains a normal rate of gastric emptying of liquids, ${ }^{17}$ and may stimulate small intestinal hyperplasia. ${ }^{18}$

Some adaptation may have occurred between six and 24 months in our patients as there was a significant weight gain of about $2 \mathrm{~kg}$ in each group during this period. Although there was no significant change in the parenteral supplements received between six and 24 months, it is interesting that at the assessment visit (median of 5 years) fewer patients with a colon needed parenteral supplements than at any previous time. Patients without a colon and less than 200 $\mathrm{cm}$ of jejunum nearly always needed daily oral or parenteral electrolyte supplements. These observations support the clinical impression that patients with a colon improve with time whereas those with a jejunostomy do not.

Most patients with a jejunostomy needed magnesium supplements; these were usually given orally and although the serum magnesium value improved, it did not usually come into the normal range.

A quarter of the patients with a functioning colon developed symptomatic renal stones. This is similar to the incidence of $21 \%$ after jejunoileal bypass for morbid obesity. ${ }^{19}$ Calcium oxalate renal stones are common because of an increased absorption of dietary oxalate ${ }^{20-22}$ in patients who have had a terminal ileal resection or disease and in whom the colon remains. ${ }^{23-25}$ Two theories exist for this increased absorption. Firstly, a mechanism that calcium may precipitate with fatty acids in the colon as insoluble calcium soaps has been suggested. ${ }^{2426}$ The intralumenal calcium concentration is thus reduced, with the result that more oxalate is in a soluble form and available for absorption. Secondly, unabsorbed bile salts and fatty acids in the lumen may increase colonic permeability to oxalate. ${ }^{27}$ No renal stones were identified in patients without a colon; this is surprising as an increased and equal incidence of both oxalate and urate renal stones has been reported in patients with an ileostomy ${ }^{28-31}$ probably relating to a state of chronic dehydration. ${ }^{32-34}$ The absence of stones in this series may reflect the large effort made to avoid dehydration in patients without a colon.

There was a high prevalence of asymptomatic gall stones in these patients (44\%). Studies looking at the prevalence of both symptomatic and asymptomatic gall stones have rarely shown a prevalence of more than $30 \%$ in any age or sex group. ${ }^{35}$ There is an increased incidence of gall stones in patients receiving parenteral nutrition. ${ }^{36}{ }^{37}$ There is also a high incidence of gall stones occurring after terminal ileal resection of about $30 \%$, which is the same whether or not the colon is present. ${ }^{38+1}$ Their formation may relate to bile salt depletion with consequent deposition of cholesterol in bile. However, this mechanism does not account for the fact that gall stones after an ileal resection, like those induced by biliary stasis, ${ }^{42}$ tend to be composed of calcium bilirubinate rather than cholesterol. ${ }^{+3}$ The higher prevalence of gall stones in men than women has been noted before in patients receiving parenteral nutrition ${ }^{37}$ and calcium bilirubinate crystals are more commonly found in men with biliary sludge than women. ${ }^{+4}$

This study shows that with the use of home 
parenteral supplements, when necessary, patients with a short intestine can be managed in reasonable health as judged by their body weight and quality of life. Preservation of the colon in these patients reduces the need for parenteral supplements, increases the incidence of renal stones, and does not change the high prevalence of gall stones.

We thank Miss Jane Brice and Dr Kay Wilkinson for their help in locating patient notes.

1 Flint JM. The effect of extensive resections of the small intestine. Bull Fohns Hopkins Hosp 1912; 23: 127-44

2 Haymond HE. Massive resection of the small intestine. An analysis of 257 collected cases. Surg Gynecol Obstet 1935; 61 : 693-705.

3 Simons BE, Jordan GL. Massive bowel resection. Am $\mathcal{F}$ Surg 1969; 118: $953-9$.

4 Nightingale JMD, Bartram CI, Lennard-Jones JE. Length of residual small bowel after partial resection: correlation between radiographic and surgical measurements. Gastrointest Radiol 1991; 16: 305-6.

5 Slater G, Aufses AH. Small bowel length in Crohn's disease. 5 Briant J Am F Gastroenterol 1991; 86: 1037-40

6 Nightingale JMD, Lennard-Jones JE, Walker ER, Farthing MJG. Jejunal efflux in short bowel syndrome. Lancet 1990 336: $765-8$.

7 Gouttebel MC, Saint-Aubert B, Astre C, Joyeux H. Total parenteral nutrition needs in different types of short bowel syndrome. Dig Dis Sci 1986; 31: 718-23.

8 Anderson CM. Long-term survival with six inches of small intestine. $B M \mathcal{F}$ 1965; 1: 419-22.

9 Martin JR, Patee CJ, Gardener C, Marien B. Massive resection of the small intestine. Can Med Assoc $\mathcal{F}$ 1953; 69: 429-33.

10 Kinney JM, Goldwyn RM, Barr JS Jr, Moore FD. Loss of the entire jejunum and ileum, and the ascending colon: management of a patient. FAMA 1962; 179: 529-32.

11 Philips SF, Giller J. The contribution of the colon to electrolyte and water conservation in man. $\mathcal{f}$ Lab Clin Med 1973; 81 $733-46$.

12 Debongnie JC, Phillips SF. Capacity of the colon to absorb fluid. Gastroenterology 1978; 74: 698-703.

13 Ladefoged K, Olgaard K. Fluid and electrolyte absorption and renin-angiotensin-aldosterone axis in patients with severe renin-angiotensin-aldosterone axis in patients with sever

14 Ladefoged K, Olgaard K. Sodium homeostasis after smallbowel resection. Scand f Gastroenterol 1985; 20: 361-9.

15 Hylander E, Ladefoged K, Jarnum S. Calcium absorption after intestinal resection. The importance of a preserved colon. Scand $\mathcal{F}$ Gastroenterol 1990; 25: 705-10

16 Ruppin H, Bar-Meir S, Soergel KH, Wood CM, Schmitt MG $\mathrm{Jr}$. Absorption of short chain fatty acids by the colon Gastroenterology 1980; 78: 1500-7.

17 Nightingale JMD, van der Sijp JRM, Kamm MA, Walker ER, Mathers SJ, Britton KE, et al. Disturbed gastric emptying in short bowel syndrome. Correlation with jejunal length and evidence for a 'colonic brake.' Gastroenterology 1991; 100 A235.

18 Miazza BM, Al-Mukhtar MYT, Salmeron M, Ghatei MA, Felce-Dachez M, Filali A, et al. Hyperenteroglucagonaemia and small intestinal mucosal growth after colonic perfusion and small intestinal mucosal growth aft

19 Hocking MP, Duerson MC, O'Leary JP, Woodward ER Jejunoileal bypass for morbid obesity. Late follow-up in 100 cases. N Englf Med 1983; 308: 995-9.
20 Stauffer JQ, Humphreys MH, Weir GJ. Acquired hyperoxaluria with regional enteritis after ileal resection. Role of dietary oxalate. Ann Intern Med 1973; 79: 383-91.

21 Chadwick VS, Modha K, Dowling RH. Mechanism for hyperoxaluria in patients with ileal dysfunction. $N$ Engl $\mathcal{F}$ Med 1973: 289: 172-6.

22 Earnest DL, Johnson G, Williams HE, Admirand WH. Hyperoxaluria in patients with ileal resection: an abnormality in dietry oxalate absorption. Gastroenterology 1974; 66: $1114-22$.

23 Dowling RH, Rose GA, Sutor DJ. Hyperoxaluria and renal calculi in ileal disease. Lancet 1971; i: 1103-6.

24 Smith $\mathrm{CH}$, Fromm H, Hofmann AF. Acquired hyperoxaluria, nephrolithiasis and intestinal disease. N Engl f Med 1972; 286: $1371-5$.

25 Dobbins JW, Binder HJ. Importance of the colon in enteric hyperoxaluria. $N$ Engl f Med 1977; 296: 298-301.

26 Andersson H, Jagenburg R. Fat-reduced diet in the treatment of hyperoxaluria in patients with ileopathy. Gut 1974; 15: 360-6.

27 Dobbins JW, Binder HJ. Effect of bile salts and fatty acids on the colonic absorption of oxalate. Gastroenterology 1976; 70: 1096-100.

28 Deren JJ, Porush JG, Levitt MF, Khilnani MT. Nephrolithiasis as a complication of ulcerative colitis and regional lithiasis as a complication of ulcerative coliti

29 Maratka Z, Nedbal J. Urolithiasis as a complication of the surgical treatment of ulcerative colitis. Gut 1964; 5: 214-7.

30 Bennett RC, Jepson RP. Uric acid stone formation following ileostomy. Aust NZ F Surg 1966; 36: 153-8.

31 Kennedy HJ, Lee ECG, Claridge G, Truelove SC. The health of subjects living with a permanent ileostomy. Qf Med 1982; 51: $341-57$.

32 Gallagher ND, Harrison DD, Skyring AP. Fluid and electrolyte disturbances in patients with long-established ileostomies. Gut 1962; 3: 219-23.

33 Clarke AM, Chirnside A. Chronic dehydration and sodium depletion in patients with established ileostomies. Lancet 1967; ii: 740-3.

34 Kennedy HJ, Al-Dujaili EAS, Edwards CRW, Truelove SC. Water and electrolyte balance in subjects with a permanent ileostomy. Gut 1983; 24: 702-5.

35 Sama C, Labate AMM, Taroni F, Barbara L. Epidemiology and natural history of gallstone disease. Semin Liver Dis 1990; 10: 149-58.

36 Roslyn JJ, Pitt HA, Mann LL, Ament ME, DenBesten L. Gallbladder disease in patients on long term parenteral nutrition. Gastroenterology 1983; 84: 148-54.

37 Pitt HA, King III W, Mann LL, Roslyn JJ, Berquist WE, Ament ME, et al. Increased risk of cholelithiasis with prolonged total parenteral nutrition. Am $\mathcal{F}$ Surg 1983; 145: prolonged 12 .

38 Heaton KW, Read AE. Gallstones in patients with disorders of the terminal ileum and disturbed bile salt metabolism. $B M \mathcal{F}$ 1969; 3: 494-6.

39 Kelly TR, Klein RL, Woodford JW. Alterations in gallstone solubility following distal ileal resection. Arch Surg 1972; 105: $352-5$.

40 Cohen S, Kaplan M, Gottlieb L, Patterson J. Liver disease and gallstones in regional enteritis. Gastroenterology 1971; 60: 237-45.

41 Hill GL, Mair WSJ, Goligher JC. Gallstones after ileostomy and ileal resection. Gut 1975; 16: 932-6.

42 Alle B, Bernhoft R, Blanckaert N, Svanvik J, Filly R, Gooding $\mathrm{G}$, et al. Sludge is calcium bilirubinate associated with bile stasis? Am F Surg 1981; 141: 51-6.

43 Pitt HA, Lewinski MA, Muller EL, Porter-Fink V, DenBesten L. Ileal resection-induced gallstones: altered biliresten $\mathrm{L}$. Ileal resection-induced gallstones: altered bili-

44 Lee SP, Nicholls JF, Park HZ. Biliary sludge as a cause of acute pancreatitis. N Englf Med 1992; 326: 589-93. 